\title{
Laser Surface Hardening of Tool Steels-Experimental and Numerical Analysis
}

\author{
Abdel-Monem El-Batahgy ${ }^{*}$, Ramadan Ahmed Ramadan ${ }^{2}$, Abdel-Rahman Moussa $^{3}$ \\ ${ }^{1}$ Manufacturing Technology Department, Central Metallurgical R \& D Institute, Cairo, Egypt; ${ }^{2}$ Spare Parts Sector, Egyptian Iron and \\ Steel Company, Helwan, Egypt; ${ }^{3}$ Mechanical Engineering Department, Faculty of Engineering, Helwan University, Helwan, Egypt. \\ Email: *elbatahgy@yahoo.com
}

Received November $15^{\text {th }}, 2012$; revised March $9^{\text {th }}, 2013$; accepted April 15 $5^{\text {th }}, 2013$

Copyright (C) 2013 Abdel-Monem El-Batahgy et al. This is an open access article distributed under the Creative Commons Attribution License, which permits unrestricted use, distribution, and reproduction in any medium, provided the original work is properly cited.

\begin{abstract}
This research work is focused on both experimental and numerical analysis of laser surface hardening of AISI M2 high speed tool steel. Experimental analysis aims at clarifying effect of different laser processing parameters on properties and performance of laser surface treated specimens. Numerical analysis is concerned with analytical approaches that provide efficient tools for estimation of surface temperature, surface hardness and hardened depth as a function of laser surface hardening parameters. Results indicated that optimization of laser processing parameters including laser power, laser spot size and processing speed combination is of considerable importance for achieving maximum surface hardness and deepest hardened zone. In this concern, higher laser power, larger spot size and lower processing speed are more efficient. Hardened zone with $1.25 \mathrm{~mm}$ depth and $996 \mathrm{HV}$ surface hardness was obtained using $1800 \mathrm{~W}$ laser power, $4 \mathrm{~mm}$ laser spot size and $0.5 \mathrm{~m} / \mathrm{min}$ laser processing speed. The obtained maximum hardness of laser surface treated specimen is $23 \%$ higher than that of conventionally heat treated specimen. This in turn has resulted in $30 \%$ increase in wear resistance of laser surface treated specimen. Numerical analysis has been carried out for calculation of temperature gradient and cooling rate based on Ashby and Easterling equations. Then, surface hardness and hardened depth have been numerically estimated based on available Design-Expert software. Numerical results indicated that cooling rate of laser surface treated specimen is high enough to be beyond the nose of the CCT diagram of the used steel that in turn resulted in a hard/martensitic structure. Numerically estimated values of surface temperature, surface hardness and hardened depth as a function of laser processing parameters are in a good agreement with experimental results. Laser processing charts indicating expected values of surface temperature, surface hardness and hardened depth as a function of different wider range of laser processing parameters are proposed.
\end{abstract}

Keywords: High Speed Tool Steels; Laser Surface Hardening; Ashby and Easterling Heat Transfer Equations; Design Expert Software; Laser Processing Charts

\section{Introduction}

Surface hardening of tool steels becomes the main factor in the face of the progressing mechanization and automation of the fabrication processes. Therefore, improvement of the surface layer of tool steels has to take fully into account the anticipated tool service conditions. When the problem of tool steels wear is addressed, their surface hardness becomes a dominant factor where the surface of the tool steels must be strong enough to resist friction forces applied to it during the operation and at the same time hard enough to resist wear. However many applications require that tool steels remains tough to withstand

${ }^{*}$ Corresponding author. impact without fracturing [1-4].

Laser surface hardening is one of the best techniques to harden a surface without sacrificing the internal toughness due to many advantages over conventional heating methods. In other words, laser surface hardening is an effective technique used to improve the tribological properties and also to increase the service life of tool steels. Surface heat treatment using laser beam is based on the characteristics of self-quenching that cools rapidly into inside of materials without using cooling medium unlike conventional surface heat treatment [5-7].

Laser beam provides localized heat input, negligible distortion, ability to treat specific areas, access to confined areas and short cycle times. It appears that laser 
surface hardening is a promising technology to avoid some of the problems encountered in traditional hardening techniques and may prove efficient in minimizing wear and extending the useful life of the tool steels and bringing on the need for an optimization procedure.

Nowadays, laser surface hardening is a subject of considerable interest because it seems to offer the chance to save strategic materials and to allow improved components with idealized surfaces and bulk engineering applications. Recently, both high power Nd-YAG lasers and $\mathrm{CO}_{2}$ lasers are employed for localized hardening of tool steel materials and hence are of potential application in machine tool industries. Many research works have been carried out to clarify the effect of the independent parameters of laser hardening process including laser power, processing speed, laser spot size as well as thermal properties of the work material [8-10].

In this respect, mathematical models are always desirable as they not only allow predicting the most suitable parameters of the laser heat treatment but also a better understanding of their relative influence on properties of heat treated material. Several approaches to the modeling of laser surface hardening have already been presented both for continuous and pulsed laser modes [11-15]. However, the subject of laser surface hardening is far from complete and many research works are needed.

The subject study is concerned with both experimental and numerical analysis of laser surface hardening of AISI M2 high speed steel as one of the most important and commonly used tool steels. Experimental analysis is focused on clarifying the effect of different laser processing parameters on the properties and performance of laser surface treated specimens. Numerical analysis is concerned with analytical approaches that provide efficient tools to obtain proper estimation of the most suitable parameters of laser surface hardening process based on Ashby and Easterling heat-transfer model [16-20] and Design-Expert software [21].

\section{Experimental Work}

The base metal used is high speed tool steel M2 according to American Iron and Steel Institute (AISI) specification. AISI M2 steel is a general purpose tool steel that offers good wear resistance with excellent toughness and cutting power. It was received in annealed condition with hardness value of $220 \mathrm{HV}$ and chemical composition shown in Table 1. Test pieces with dimensions of $30 \times$ $20 \times 10 \mathrm{~mm}$ each were cut from the as-received base metal and prepared for laser surface hardening experiments.

The laser system used is CW Nd-YAG laser with 2.2 kW maximum output power. Gaussian energy density distribution was defocused on surface of test specimens to obtain different spot size diameters of laser beam. Laser surface hardening experiments were carried out using laser parameters shown in Table $\mathbf{2}$ where a singly track was produced for each specimen. The used laser surface hardening parameters are laser powers of 400, 800, 1200, 1600 and $1800 \mathrm{~W}$, spot sizes of $1,2,3$ and $4 \mathrm{~mm}$ and corresponding processing speeds of $4,2,1$ and $0.5 \mathrm{~m} / \mathrm{min}$ respectively. Argon with $10 \mathrm{l} / \mathrm{min}$ flow rate was used as a shielding gas.

Based on these laser processing parameters, hardened layers with different surface temperatures, surface hardness, hardened depths, and microstructures were obtained. In general, laser processing parameters were properly selected to avoid melting at specimen surface, which is normally undesirable during surface hardening. Laser surface treated specimens were cross sectioned and prepared for macro- and microscopic investigations, hardness measurements, wear test, energy dispersive x-ray (EDX) microanalysis and $\mathrm{x}$-ray diffraction (XRD). Surface hardness, depth and width of hardened layer as well as its microstructures were clarified as a function of different laser processing parameters.

The obtained experimental results were confirmed using two numerical approaches. The first approach is the Ashby and Easterling heat-transfer model that is concerned with calculation of temperature gradient and cooling rate. The second approach is based on available Design-Expert software that was used for prediction of surface temperature, surface hardness and hardened depth.

\section{Results and Discussion}

\subsection{Experimental Analysis}

In order to clarify effect of laser power on surface hardness, hardened depth and width, as well as microstructure of laser heat treated zone, the laser power was changed

Table 1. Chemical composition (wt\%) of used tool steel together with specified range for AISI M2 steel [1].

\begin{tabular}{|c|c|c|c|c|c|c|c|}
\hline Material Element & $\mathrm{C}$ & $\mathrm{Si}$ & Mn & $\mathrm{Cr}$ & Mo & V & W \\
\hline Used tool steel ${ }^{*}$ & 0.91 & 0.27 & 0.3 & 3.45 & 4.8 & 1.85 & 6.7 \\
\hline AISI M2 steel & $0.78-1.05$ & $0.20-0.45$ & $0.15-0.40$ & $3.75-4.50$ & $4.50-5.50$ & $1.75-2.20$ & $5.50-6.75$ \\
\hline
\end{tabular}

${ }^{*} \mathrm{~S}(0.01 \%)$ and $\mathrm{P}(0.01 \%)$ are within the specified range $(0.03 \mathrm{max})$. 
Table 2. Laser surface hardening parameters used.

\begin{tabular}{ccc}
\hline $\begin{array}{c}\text { Power } \\
(\mathrm{W})\end{array}$ & $\begin{array}{c}\text { Laser beam spot size } \\
(\mathrm{mm})\end{array}$ & $\begin{array}{c}\text { Laser processing } \\
\text { speed }(\mathrm{m} / \mathrm{min})\end{array}$ \\
\hline & 1 & 4 \\
$400,800,1200$, & 2 & 2 \\
1600,1800 & 3 & 1 \\
& 4 & 0.5 \\
\hline
\end{tabular}

within the range $400-1800 \mathrm{~W}$. Figure 1 shows an example of macrographs of cross sections taken from laser surface heat treated specimens produced using $4 \mathrm{~mm}$ laser beam spot size, $0.5 \mathrm{~m} / \mathrm{min}$ processing speed and two different laser powers (400 and $1800 \mathrm{~W}$ ). It is clear that both depth and width of the laser hardened zone increase with increasing laser power. Increasing laser power from $400 \mathrm{~W}$ (Figure 1(a)) to $1800 \mathrm{~W}$ (Figure 1(b)) resulted in approximately two times increase in both depth and width of hardened zone. This is attributed mainly to considerable increase in heat input. On the other hand, the hardened depth and width decreased with increasing either processing speed or laser beam spot size as a result of decreasing heat input. It is obvious that laser power, laser spot size and processing speed have distinct influence on both depth and width of hardened zone. These results are in a good agreement with other research works $[8,10]$.

Results of surface hardness measurements of laser surface heat treated specimens as a function of laser power and laser beam spot size-processing speed combi- nation are shown in Figure 2. It can be noticed that sur- face hardness of laser surface treated specimens is re- markably affected by laser power. Regardless of laser spot size-processing speed combination, surface hardness was increased from $200-400 \mathrm{HV}$ to $800-1000 \mathrm{HV}$ with increasing laser power from $400 \mathrm{~W}$ to $1800 \mathrm{~W}$, respectively. Increasing laser power above $1800 \mathrm{~W}$ resulted in decreasing surface hardness regardless of laser spot sizeprocessing speed combination. This is attributed to excess heat input that is high enough to cause partial melting at surface, which in turn results in inhomogeneous microstructure with lower hardness.

Surface hardness is inversely proportional to processing speed and laser spot size where it was increased with decreasing either processing speed or laser spot size. However, small laser spot size-high processing speed combination is effective at low laser power range (less than $1200 \mathrm{~W}$ ). Large laser spot size-low processing speed combination is effective at high laser power range (higher than $1200 \mathrm{~W}$ ).

It should be mentioned that the surface hardness values $(800-1000 \mathrm{HV})$ obtained at $1800 \mathrm{~W}$ laser power are high enough for acceptable performance regardless of
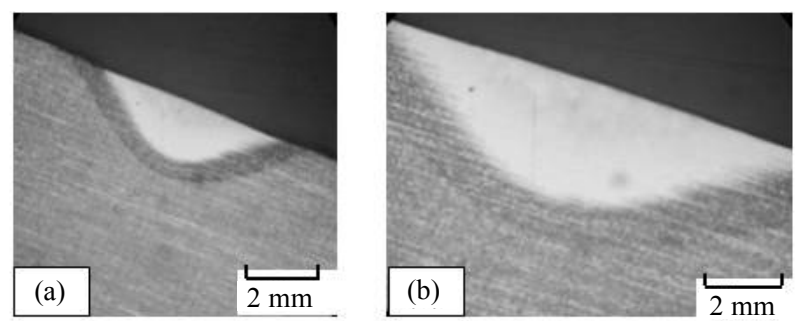

Figure 1. Macrographs of cross sections taken from laser surface heat treated specimens produced using $4 \mathrm{~mm}$ laser spot size, $0.5 \mathrm{~m} / \mathrm{min}$ processing speed and two different laser powers. (a) $400 \mathrm{~W}$; (b) $1800 \mathrm{~W}$.

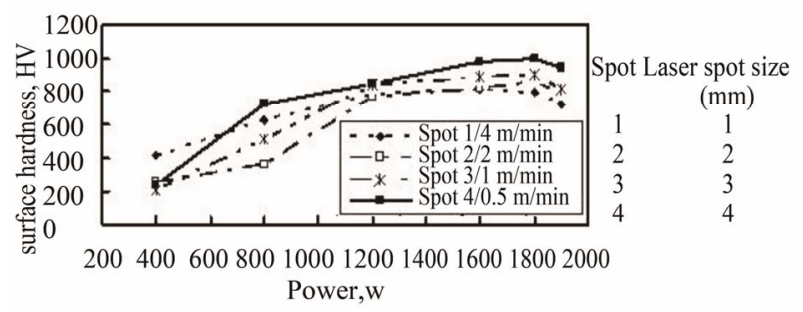

Figure 2. Surface hardness of laser surface heat treated specimens as a function of laser power and laser spot sizeprocessing speed combination.

laser spot size-processing speed combination. These hardness values are substantially higher than that resulted from conventional heat treatment $(700-800 \mathrm{HV})$.

These results indicate that optimization of laser power, laser spot size and processing speed combination is of considerable importance for having surface temperature high enough for complete austenitization and interaction time sufficient for complete homogenization that in turn results in homogeneous hard microstructure. These parameters are equally important to achieve optimum hardness and adequate hardened depth.

Figure 3 shows hardness profile as a function of distance from laser heat treated surface and laser power. Laser spot size-processing speed combination was kept constant at $4 \mathrm{~mm}$ and $0.5 \mathrm{~m} / \mathrm{min}$ respectively. For the whole laser power range used (1200 - $1800 \mathrm{~W})$, maximum hardness values of $800-1000 \mathrm{HV}$ were obtained at surface then, hardness values were decreased with increasing distance from surface. It can be noticed also that the higher laser power $(1800 \mathrm{~W})$ has resulted in higher hardness at surface as well as through thickness that means deeper hardened zone. It should be reported that depth and width of laser hardened zone were decided based on a minimum hardness value of $400 \mathrm{HV}$ that is higher enough than that of base metal (220 HV).

Figure 4 shows hardened depth as a function of laser power and laser spot size-processing speed combination. It is obvious that increasing laser power resulted in increasing hardened depth regardless of laser spot sizeprocessing speed combination. However, larger laser 


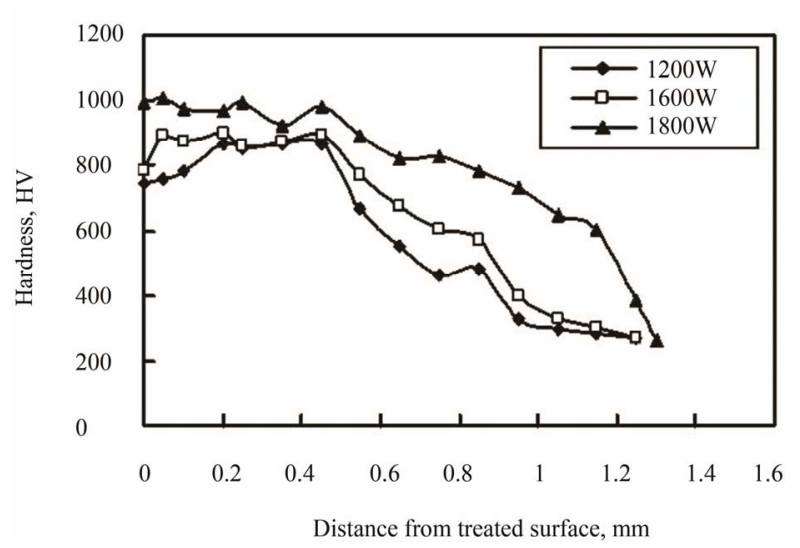

Figure 3. Hardness as a function of distance from laser treated surface and laser power at $4 \mathrm{~mm}$ laser spot size- 0.5 $\mathrm{m} / \mathrm{min}$ processing speed combination.

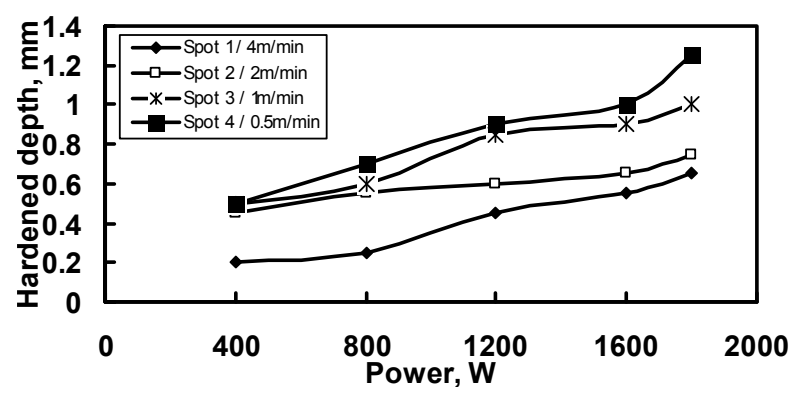

Figure 4. Hardened depth as a function of laser power and laser spot size-processing speed combination.

spot size $(4 \mathrm{~mm})$-lower processing speed $(0.5 \mathrm{~m} / \mathrm{min})$ combination resulted in deepest hardened zone regardless of laser power used.

It should be reported that similar results were obtained concerning the effect of laser power and laser spot size-processing speed combination on width of hardened zone. Generally, width of hardened zone is about twice its depth. Hardened depth and width were decreased with increasing processing speed at constant laser power and laser spot size. It is clear that both depth and width of the hardened zone are proportional to laser power, laser spot size, and inversely to traverse speed. However, this is only true as long as the austenitization of the hardened tool steel is not complete as has been reported in other research works $[6,7]$.

The deepest hardened zone with $1.25 \mathrm{~mm}$ depth was obtained using $4 \mathrm{~mm}$ laser spot size- $0.5 \mathrm{~m} / \mathrm{min}$ processing speed combination and $1800 \mathrm{~W}$ laser power (Figure 4). In other words, increasing laser power, laser spot size and decreasing processing speed results in increasing the hardened depth. This means that larger spot size, lower processing speed and higher laser power are more efficient concerning deeper hardened depth. However, the hardened zone depth can not be indefinitely increased with increasing laser power or decreasing processing speed at a constant laser spot size because the surface will start showing partial melting at a certain case depth limit. Thus the maximum hardened depth, which can be achieved using small laser spot size, will be less than that can be achieved in case of large laser spot size with maximum power. This could be attributed to formation of inhomogeneous microstructure as a result of partial melting in case of smaller laser spot size that means higher beam density.

Performance of some selected laser surface treated specimens was evaluated using a pin-on-disc wear testing machine. This selection was based on both higher surface hardness and deeper hardened zone. In this concern, specimens produced using $1600 \mathrm{~W}, 3 \mathrm{~mm}$ laser spot size $-1 \mathrm{~m} / \mathrm{min}$ processing speed combination and $1800 \mathrm{~W}$ laser power, $4 \mathrm{~mm}$ laser spot size- $0.5 \mathrm{~m} / \mathrm{min}$ processing speed combination were selected. Weight loss technique was measured using a Sartorius AE 200 microbalance of $10^{-4} \mathrm{~g}$ sensitivity and $160 \mathrm{~g}$ maximum weight. Results of wear test of laser surface treated specimens as a function of laser power and laser spot size-processing speed combination are shown in Figure 5. For comparison, results of wear test of a conventionally heat treated specimen and as-received base metal are included.

The most important notice is the lowest weight loss that means highest wear resistance for laser surface treated specimens in comparison with both conventionally heat treated specimen and as-received base metal. Maximum wear resistance can be achieved using either $1600 \mathrm{~W}, 3 \mathrm{~mm}$ laser spot size- $1 \mathrm{~m} / \mathrm{min}$ processing speed combination or $1800 \mathrm{~W}$ laser power, $4 \mathrm{~mm}$ laser spot size- $0.5 \mathrm{~m} / \mathrm{mn}$ processing speed combination. Wear resistance of laser surface treated specimens is about $30 \%$ higher than that of conventionally heat treated specimen and about $90 \%$ higher than that of untreated base metal. It is believed that the high hardness level obtained in case of laser surface heat treated specimens is responsible for high wear resistant of these specimens. Besides, it is suggested that temperature increase due to friction

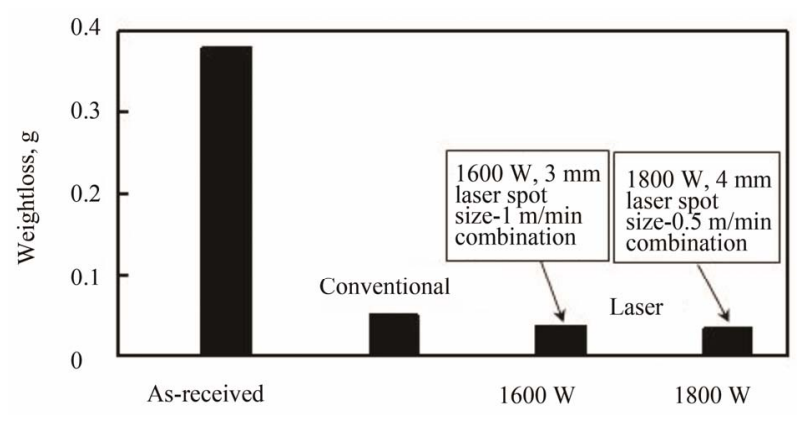

Figure 5. Wear behavior of laser surface treated specimens as a function of laser processing parameters, together with that of conventionally heat treated specimen and as-received base metal. 
during sliding action will further increase the hardness by tempering the martensite to a homogeneous microstructure, thus resulting in good wear resistance [5].

Results of both hardness measurements and wear test have been confirmed using optical and scanning electron microscopic examinations. An example of optical and scanning electron micrographs of a cross section taken from laser surface treated specimen produced using 1800 $\mathrm{W}$ and $4 \mathrm{~mm}$ laser spot size- $0.5 \mathrm{~m} / \mathrm{min}$ processing speed combination is shown in Figure 6. It is clear that the microstructure consists of three distinct regions; hardened zone (HZ), heat affected zone (HAZ) and unaffected base metal (BM).

Hardened zone exhibited fine martensite and carbides that in turn resulted in higher hardness level and subsequently higher wear resistance. Heat affected zone consists of a partially austenitized and eventually hardened structure in addition to material fractions that did not transform to austenite during laser irradiation, which in turn resulted in lower hardness. The base metal with its original soft microstructure has a hardness value of 220 HV.

\subsection{Numerical Analysis}

Based on experimentally obtained optimum laser processing parameters (1800 W laser power, $4 \mathrm{~mm}$ laser spot size and $0.5 \mathrm{~m} / \mathrm{min}$ laser processing speed), numerical analysis has been carried out for calculation of surface temperature and cooling rate of laser surface treated specimen. This has been done using Ashby and Easterling heat-transfer equations that rely on the solution of a heat conduction problem to obtain the quasi-steady temperature distribution in the material. The calculated surface temperature was confirmed using available Design-Expert software that was subsequently used for estimation of wide range of surface temperatures, surface hardness and hardened depth as a function of different laser processing parameters.

\subsubsection{Ashby and Easterling Heat Transfer Model}

Based on Ashby and Easterling heat transfer equations, temperature at which austenitization and subsequent martensite formation takes place can be calculated. Temperature gradient through thickness as a function of distance from surface of laser treated specimen was calculated using the following Ashby and Easterling heat transfer equations [16-20].

$$
\begin{aligned}
& \mathrm{T}-\mathrm{T}_{\mathrm{o}}=\mathrm{Aq} / 2 \pi \lambda \mathrm{v}\left[\mathrm{t}\left(\mathrm{t}+\mathrm{t}_{\mathrm{o}}\right)\right]^{1 / 2} \\
& \mathrm{x} \exp \left\{-1 / 4 \alpha\left[\left(\mathrm{z}+\mathrm{z}_{\mathrm{o}}\right)^{2} / \mathrm{t}+\mathrm{y}^{2}\right] /\left(\mathrm{t}+\mathrm{t}_{\mathrm{o}}\right)\right\}
\end{aligned}
$$

where $T$ is the specimen temperature just at the end of laser surface heat treatment process, $T_{0}$ is the specimen temperature before starting laser surface heat treatment process, $\mathrm{A}$ is the absorbtivity, $\mathrm{q}$ is the laser power, $\lambda$ and $\alpha$ are the thermal conductivity and diffusivity, $v$ is the processing speed, $t$ is the laser-material interaction time, $t_{o}$ is a diffusion related constant time, $y$ and $z$ are the Cartesian coordinates, $z_{0}$ is a constant characteristic length. The instantaneous heating and cooling rates were calculated using the following equation.

$$
\begin{aligned}
\mathrm{dT} / \mathrm{dt}= & \left(\mathrm{T}-\mathrm{T}_{\mathrm{o}} / \mathrm{t}\right)\left\{\left[\left(\mathrm{z}+\mathrm{z}_{\mathrm{o}}\right)^{2} / 4 \alpha \mathrm{t}\right]\right. \\
& {\left.\left[(1 / 2)\left(2 \mathrm{t}+\mathrm{t}_{\mathrm{o}} / \mathrm{t}+\mathrm{t}_{\mathrm{o}}\right)\right]\right\} }
\end{aligned}
$$

The first term in the brackets describes heating while the second term describes cooling. In this regard, both thermo-physical parameters given in Table 3 and previously obtained experimental results were used for substitution in these equations where the temperature changes at different depths below heat treated surface were calculated.

Based on Equation (1) and experimentally obtained optimum laser processing parameters (1800 W laser
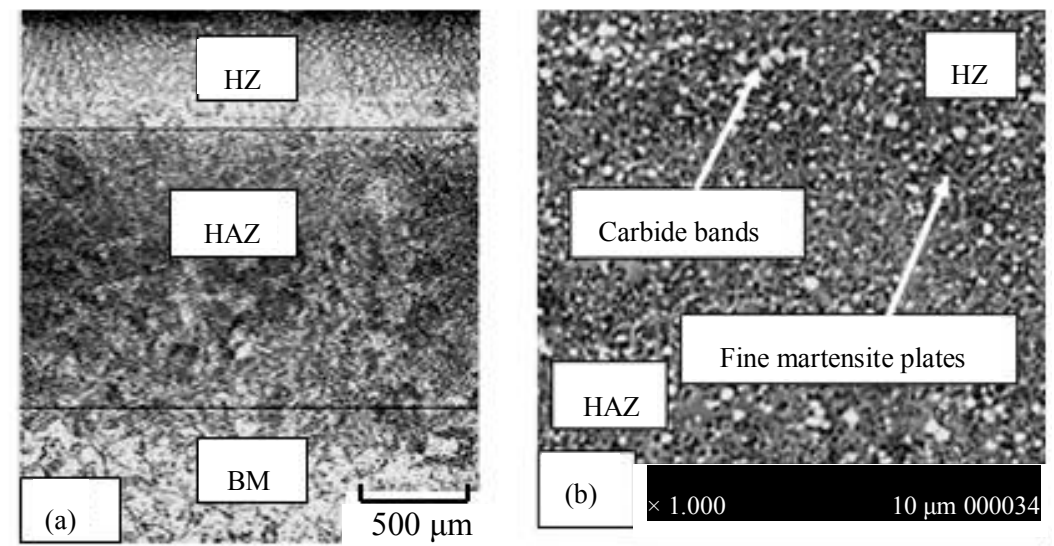

Figure 6. Optical (a) and scanning electron (b) micrographs of a cross section of laser surface treated specimen produced using $1800 \mathrm{~W}, 4 \mathrm{~mm}$ laser spot diameter- $0.5 \mathrm{~m} / \mathrm{min}$ processing speed combination. 
Table 3. Thermo-physical parameters of used AISI M2 high speed tool steel [1].

\begin{tabular}{cc}
\hline Property & Value \\
\hline Thermal conductivity, $\lambda(\mathrm{W} / \mathrm{mK})$ & 28.0 \\
Heat capacity, c $(\mathrm{J} / \mathrm{kg} \mathrm{K})$ & 674 \\
Thermal diffusivity, $\alpha\left(\mathrm{m}^{2} / \mathrm{s}\right)$ & $5.1 \times 10^{-3}$ \\
Density, $\rho\left(\mathrm{kg} / \mathrm{m}^{3}\right)$ & 8000 \\
Ms, $\left({ }^{\circ} \mathrm{C}\right)$ & $1100-1230$ \\
Mustenitized temperature, $\mathrm{TA}\left({ }^{\circ} \mathrm{C}\right)$ & 225 \\
Carbon content in steel, $(\mathrm{wt} \%)$ & 1568 \\
\hline
\end{tabular}

calculated and found to be equal to $2274^{\circ} \mathrm{C} / \mathrm{sec}$. This power, $4 \mathrm{~mm}$ laser spot size, $0.5 \mathrm{~m} / \mathrm{min}$ processing speed) where the hardened zone is $1.25 \mathrm{~mm}$ depth, surface temperature of $1266^{\circ} \mathrm{C}$ was obtained. According to Equation (2), the cooling rate from this surface temperature was calculated cooling rate is high enough to be beyond the nose of the CCT diagram of AISI M2 high speed tool steel that in turn results in a fully martensitic structure [1].

Accordingly, any other isothermal temperature line within the measured hardened depth; between the calculated surface temperature $\left(1266^{\circ} \mathrm{C}\right)$ and $\mathrm{AC} 1$ temperature $\left(723^{\circ} \mathrm{C}\right)$ can be estimated. For $1000^{\circ} \mathrm{C}$, the calculations indicated that this isothermal temperature line is located $0.61 \mathrm{~mm}$ below the specimen surface and its cooling rate is $2000^{\circ} \mathrm{C} / \mathrm{sec}$. For AC3 temperature $\left(790^{\circ} \mathrm{C}\right)$, the calculations indicated that this isothermal temperature line is located $1.087 \mathrm{~mm}$ below the specimen surface and its cooling rate is $1700^{\circ} \mathrm{C} / \mathrm{sec}$.

Figure 7 shows summary of calculated temperature gradient and cooling rate as a function of distance from surface of laser treated specimen produced using optimum laser processing parameters including $1800 \mathrm{~W}, 4$ $\mathrm{mm}$ laser spot size and $0.5 \mathrm{~m} / \mathrm{min}$ processing speed. It is clear that both calculated temperature and cooling rate decreases with increasing distance from specimen surface. These results are in a good agreement with the results of experimental work. This means that numerical analysis is of considerable accuracy in addition to its economical aspects. Subsequently, such numerical analysis can be used for calculations of surface temperature and cooling rate of other different laser processing parameters.

\subsubsection{Design Expert Software}

The surface temperature $\left(1266^{\circ} \mathrm{C}\right)$ calculated using Ashby and Easterling heat transfer equations was confirmed using the available Design-Expert software [21]. Then, wide range of surface temperatures was estimated and finally surface hardness and hardened depth of heat treated specimens were calculated using the same soft-

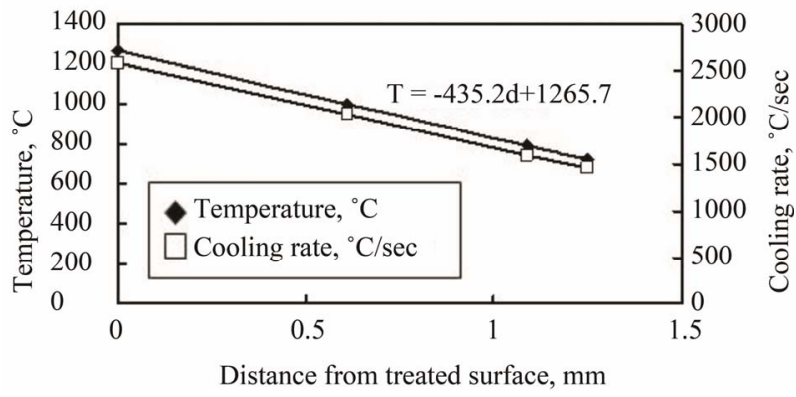

Figure 7. Calculated temperature gradient and cooling rate through hardened depth of laser surface treated specimen produced using optimum laser processing parameters $(1800$ $\mathrm{W}, 4 \mathrm{~mm}$ laser spot size and $0.5 \mathrm{~m} / \mathrm{min}$.

ware. Input data for this software included all experimentally used laser processing parameters including laser power, laser spot size and processing speed. However, the optimum results of this software were obtained within a limited range of laser processing parameters that are $1200-1800 \mathrm{~W}$ power, $4 \mathrm{~mm}$ laser spot size and 0.5 $\mathrm{m} / \mathrm{min}$ processing speed.

Numerical results concerning surface temperature, surface hardness and hardened depth estimated using the software are plotted in Figures 8-10 as a function of laser power at $4 \mathrm{~mm}$ laser spot size and $0.5 \mathrm{~m} / \mathrm{min}$ processing speed. Experimental results are also included for comparison. It is clear that the numerically estimated values of surface temperature, surface hardness and hardened depth are very close to those experimentally obtained results. In other words, both numerical and experiments results are in a good agreement with each other.

Based on the above results of both experimental work and numerical calculations, laser processing charts indicating expected values of surface temperature, surface hardness and hardened depth as a function of different wider range of laser processing parameters are proposed as shown in Figures 11-13 respectively. These figures summarize the relation between different laser processing parameters and surface temperature, surface hardness and hardened depth of laser surface treated specimens. It can be noticed that increasing laser power as well as laser spot size and decreasing laser processing speed will result in increasing surface temperature, surface hardness and hardened depth. Generally, surface temperature, surface hardness and hardened depth of laser surface treated specimens can be predicted based on laser power, laser spot size and processing speed combination as shown in the proposed laser processing charts. It is known that numerical analysis is of remarkable importance regarding results accuracy as well as economical aspects.

\section{Conclusions}

Based on the results achieved in this investigation, the 


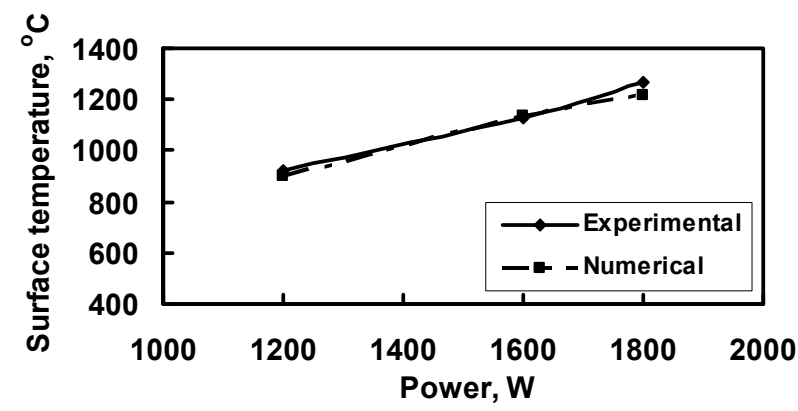

Figure 8. Experimental and numerical results of surface temperature as a function of laser power at $4 \mathrm{~mm}$ laser spot size- $0.5 \mathrm{~m} / \mathrm{min}$ processing speed combination.

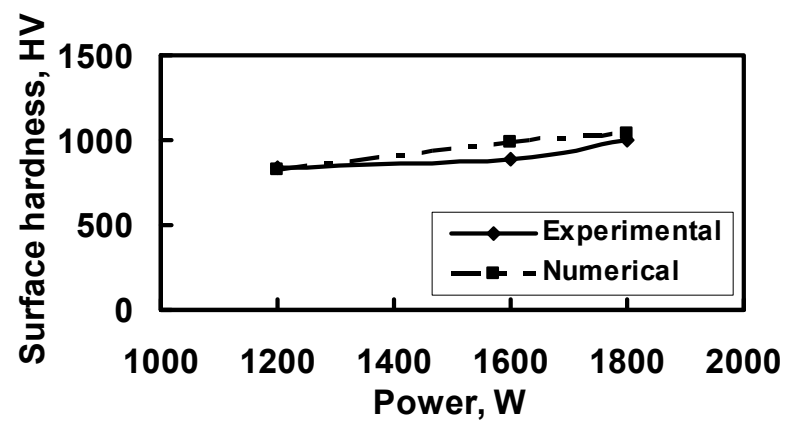

Figure 9. Experimental and numerical results of surface hardness as a function of laser power at $4 \mathrm{~mm}$ laser spot size- $0.5 \mathrm{~m} / \mathrm{min}$ processing speed combination.

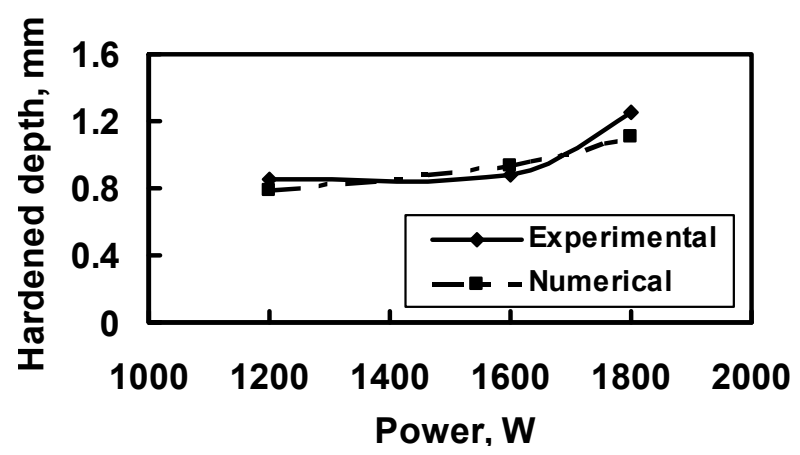

Figure 10. Experimental and numerical results of hardened depth as a function of laser power at $4 \mathrm{~mm}$ laser spot size- $0.5 \mathrm{~m} / \mathrm{min}$ processing speed combination.

following conclusions can be drawn:

Optimization of laser processing parameters including laser power, laser spot size and processing speed combination is of considerable importance for achieving maximum surface hardness and deepest hardened zone. In other words, laser processing parameters should be optimized for having surface temperature high enough for complete austenitization, without partial surface melting that in turn results in a homogeneous hard microstructure. Hardened zone with $1.25 \mathrm{~mm}$ depth and 996 $\mathrm{HV}$ surface hardness was produced using $1800 \mathrm{~W}$ laser power, $4 \mathrm{~mm}$ laser spot size and $0.5 \mathrm{~m} / \mathrm{min}$ laser

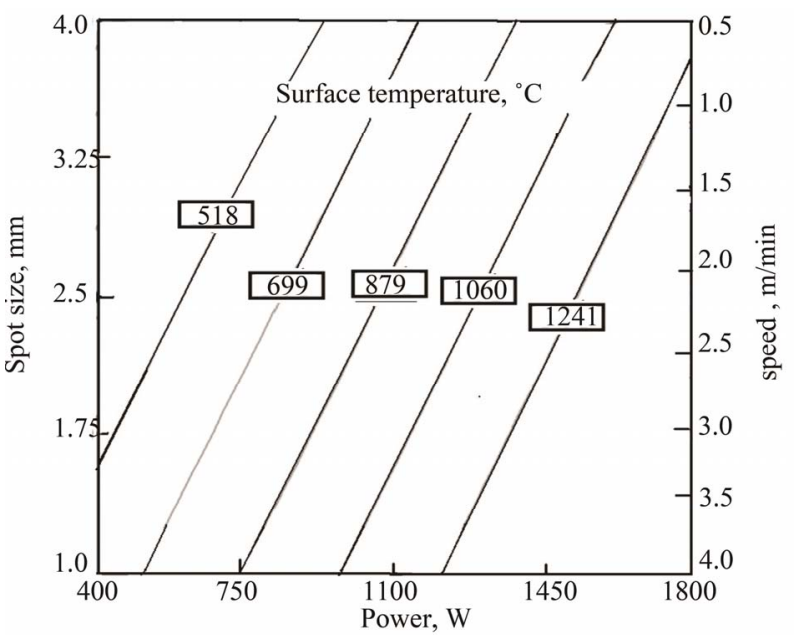

Figure 11. Prediction of surface temperature based on laser power, processing speed and laser spot size combination.

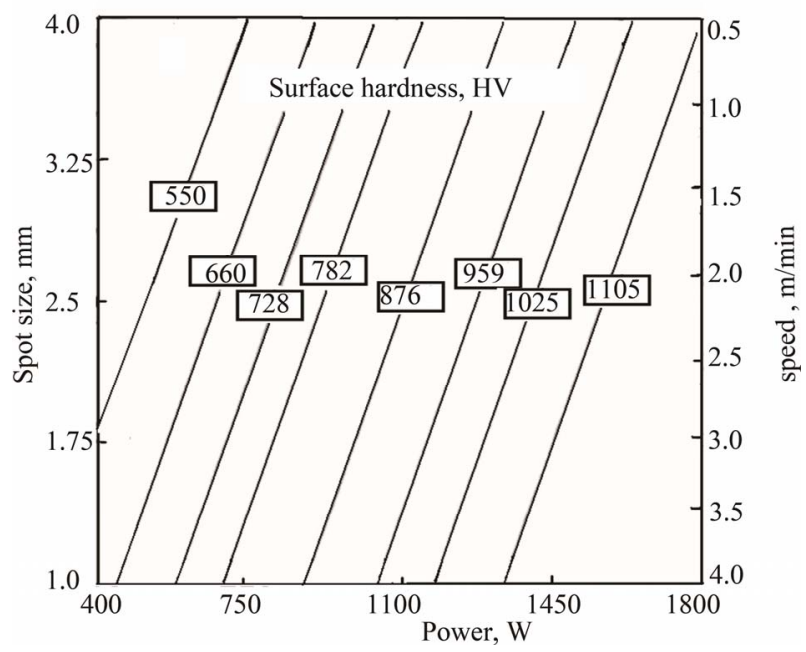

Figure 12. Prediction of surface hardness based on laser power, processing speed and laser spot size combination.

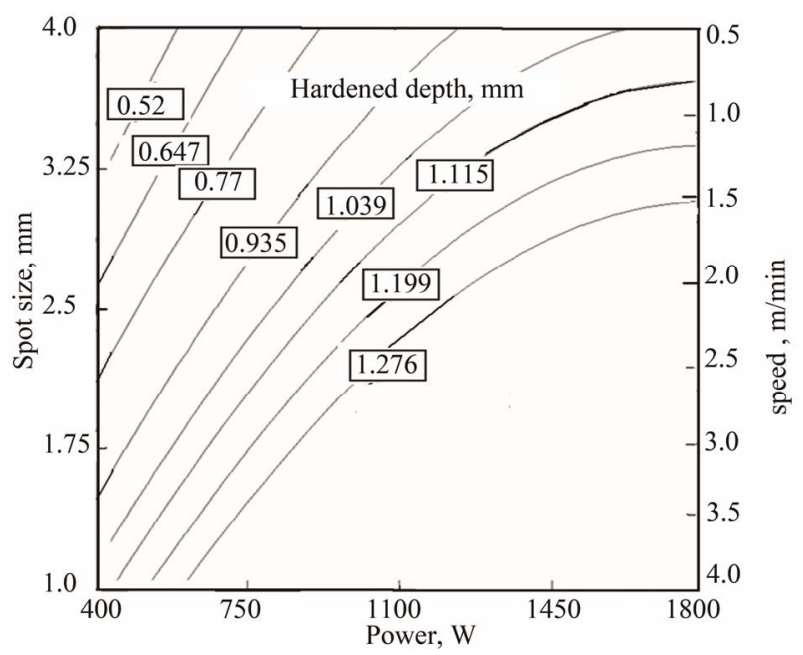

Figure 13. Prediction of hardened depth based on laser power, processing speed and laser spot size combination. 
processing speed. The obtained maximum hardness of laser surface treated specimen is $23 \%$ higher than that of conventionally heat treated one. In general, higher laser power, larger spot size and lower processing speed are more efficient for obtaining deeper hardened depth.

Wear resistance of laser surface treated specimen is $30 \%$ higher than that of conventionally heat treated one and $90 \%$ higher than that of untreated base metal. Such higher wear resistance in case of laser surface treatment is related to higher hardness as a result of fine martensite and chromium carbides in the hardened zone.

Numerical analysis has been carried out for calculation of temperature gradient and cooling rate based on Ashby and Easterling equations. Then, surface hardness and hardened depth have been numerically estimated based on available Design-Expert software. Numerical results indicated that cooling rate of laser surface treated specimen is high enough to be beyond the nose of the CCT diagram of the used tool steel that in turn resulted in a hard/martensitic structure.

Numerically estimated values of surface temperature, surface hardness and hardened depth as a function of laser processing parameters are in a good agreement with experimental results. Since numerical analysis is of considerable importance regarding economical aspects then, laser processing charts indicating expected values of surface temperature, surface hardness and hardened depth as a function of different wider range of laser processing parameters are proposed.

\section{REFERENCES}

[1] R. Wilson, "Metallurgy and Heat Treatment of Tool Steels," McGraw-Hill Book Company Limited, London, UK, 1975.

[2] D. N. Collins, "Deep Cryogenic Treatment of Tool Steels: A Review," Heat Treatment of Metals, No. 2, 1996, pp. 40-42.

[3] A. Molinari, M. Pellizzari, S. Gialanella, G. Straffelini and K. H. Stiasny, "Effect of Deep Cryogenic Treatment on the Mechanical Properties of Tool Steels," Journal of Materials Processing Technology, Vol. 118, No. 1, 2001, pp. 350-355.

[4] Y. Lakhtin, "Engineering Physical Metallurgy," Mir Publishers, Moscow, 1971.

[5] C. T. Kwok, et al., "Microstructural and Corrosion Characteristics of Laser Surface-Melted Plastics Mold Steels," Materials Science and Engineering: A, Vol. 357, No. 1-2, 2003, pp. 94-103. doi:10.1016/S0921-5093(03)00228-4

[6] H. J. Shina, et al., "Microstructural and Hardness Investigation of Hot-Work Tool Steels by Laser Surface Treatment," Journal of Materials Processing Technology, Vol. 201, No. 1-3, 2008, pp. 342-347. doi:10.1016/j.jmatprotec.2007.11.232

[7] K. Obergfell, V. Schulze and O. Vohringer, "Classification of Microstructural Changes in Laser Hardened Steel
Surfaces," Materials Science and Engineering: A, Vol. 355, No. 1-2, 2003. pp. 348-356. doi:10.1016/S0921-5093(03)00099-6

[8] H. Pantsar, et al., "Effect of Processing Parameters on the Microstructure and Hardness of Laser Transformation Hardened Tool Steel," Proceedings of the 23rd International Congress on Applications of Laser and ElectroOptics (ICALEO 2004), San Francisco, California, USA, 4-7 October 2004, pp. 565-573.

[9] G. H. Shehata, "Development of Hard Cutting Tools by Laser Processing," Ph.D. Dissertation, Helwan University, Cairo, Egypt, 1992.

[10] M. S. Elnewishy, "Study on Laser Surface Treatment of Different Tool Steels," M.Sc. Dissertation, Cairo University, Egypt, 2006.

[11] N. Cheung, et al., "Mathematical Modeling and Experimental Analysis of the Hardened Zone in Laser Treatment of AISI 1045 Steel," Materials Research, Vol. 7, No. 2, 2004, p. 349. doi:10.1590/S1516-14392004000200022

[12] M. J. Tobar, C. Álvarez, J. M. Amado, A. Ramil, E. Saavedra and A. Yáñez, "Laser Transformation Hardening of a Tool Steels: Simulation-Based Parameter Optimization and Experimental Results," Surface and Coatings Technology, Vol. 200, No. 22-23, 2006, pp. $6362-$ 6367. doi:10.1016/j.surfcoat.2005.11.067

[13] R. Komanduri and Z. B. Hou, "Thermal Analysis of Laser Surface Transformation Hardening-Optimization of Process Parameters," International Journal of Machine Tools and Manufacture, Vol. 44, No. 9, 2004, pp. 991-1008.

[14] R. Patwa and Y. C. Shin, "Predictive Modeling of Laser Hardening of AISI51 50H Steels," International Journal of Machine Tools and Manufacture, Vol. 47, No. 2, 2007, pp. 307-320. doi:10.1016/j.ijmachtools.2006.03.016

[15] B. Yilbas, et al., "Laser Melting of Carbide Tool Surface: Model and Experimental Studies," Applied Surface Science, Vol. 255, No. 23, 2009, pp. 9396-9403. doi:10.1016/i.apsusc.2009.07.042

[16] M. Ashby and K. Easterling, "A First Report on Diagrams for Grain Growth in Welds," Acta Metallurgica, Vol. 30, No. 11, 1982, pp. 1969-1978. doi:10.1016/0001-6160(82)90100-6

[17] J. Ion, K. Easterling and M. Ashby, "A Second Report on Diagrams of Microstructure and Hardness for Heat-Affected Zones in Welds," Acta Metallurgica, Vol. 32, No. 11, 1984, pp. 1949-1955, 1957-1962. doi:10.1016/0001-6160(84)90176-7

[18] S. Kou, "Heat Flow in Welding, Welding Metallurgy," Wiley-Interscience, Hoboken, 2003.

[19] J. Selvan, K. Subramanian and A. Nath, "Effect of Laser Surface Hardening on EN18 (AISI 5135) Steel," Journal of Materials Processing Technology, Vol. 91, No. 1-3, 1999, pp. 29-36. doi:10.1016/S0924-0136(98)00430-0

[20] K. Poorhaydari, B. Patchett and D. Ivey, "Estimation of Cooling Rate in the Welding of Plates with Intermediate Thickness," Welding Journal, Vol. 84, No. 10, 2005, pp. $149 \mathrm{~s}-155 \mathrm{~s}$

[21] "Design Expert Software, Version 6.0.5," Serial No. W6XY2291. www.statease.com 